\title{
Inundation of saline supratidal mudflats provides an important source of carbon and nutrients in an aquatic system
}

\author{
M. A. Burford ${ }^{1, *}$, D. Valdez ${ }^{1}$, G. Curwen ${ }^{1}$, S. J. Faggotter ${ }^{1}$, D. P. Ward ${ }^{1}$, K. R. O'Brien ${ }^{2}$ \\ ${ }^{1}$ Australian Rivers Institute, Griffith University, Kessels Rd, Nathan, QLD 4111, Australia \\ ${ }^{2}$ School of Chemical Engineering, The University of Queensland, St Lucia, QLD 4075, Australia
}

\begin{abstract}
Supratidal mudflats are a poorly understood habitat adjacent to coastal areas and are under pressure from human development and climate change. These habitats are only inundated infrequently but may be important contributors to coastal productivity. This study determined nutrient release and primary productivity (PP) on a large, pristine supratidal mudflat in the wetdry tropics of Australia. Results of experimental studies on nutrient release and PP upon freshwater inundation were incorporated into a simple model of supratidal mudflat inundation based on remote sensing data and long-term river height data. The model was used to hind-cast potential annual primary production and nutrient release for a period capturing high and low inundation years. Our experimental studies measured a rapid release of nitrate, ammonium and phosphate in the first $2 \mathrm{~d}$ after inundation. Some days later there was measurable algal growth. Incorporating this data into the model showed that the main driver for the whole-system PP rates was the areal extent of inundation, rather than the duration of inundation, provided that inundation lasted longer than the minimum period for primary production to occur. The same was true for nutrient release although a shorter period of inundation was needed for release to occur. Future changes in flow and associated flooding, as a result of climate change and/or water resource development, could therefore have significant effects on productivity in these coastal systems.
\end{abstract}

KEY WORDS: Primary productivity $\cdot$ Benthic algae $\cdot$ Nitrogen $\cdot$ Phosphorus

\section{INTRODUCTION}

Coastal supratidal mudflats, otherwise known as supratidal mudflats or sabkhas (Briere 2000) are shallow coastal habitats only infrequently tidally inundated. However, during large rainfall events which result in overbank flow, or sustained local rainfall, they may be flooded for extended periods. There has been wide scale destruction and degradation of these habitats around the world due to human pressures on coastal areas (Halpern et al. 2008), including infilling for urban and agricultural development. Despite this, there is insufficient acknowledgement of their ecological value to coastal and estuarine ecosystems (Albuquerque et al. 2014).

Wet-dry tropical areas of Australia have extensive areas of supratidal mudflats which remain relatively pristine, and can therefore provide insights into the ecological value of this habitat. The few studies have shown that contributions of these habitats to coastal nutrient and carbon (C) biogeochemistry can be significant (Lovelock et al. 2010, Adame et al. 2012). The land adjacent to the Gulf of Carpentaria contains thousands of square kilometres of low-lying, supra- 
tidal mudflats which are mostly vegetation free, and are coated in a salt crust for most of the year (Rhodes 1980). This habitat contains benthic algal species which remain dormant until there is rainfall and/or flooding, after which time algal growth occurs, although this has not previously been quantified. The nutrient biogeochemistry underpinning the algal growth is also poorly known with the exception of a study in the 1980s which found nutrient outwelling to adjacent coastal areas upon inundation (Ridd et al. 1988). It is likely that inundation of supratidal mudflats contributes to nutrient release fuelling primary production in the land-water interface of these coastal areas.

Our study therefore examined primary productivity (PP) and nutrient release from supratidal mudflats adjacent to an estuary in the Gulf of Carpentaria over 2 yr. We hypothesized that supratidal mudflats are a source of nutrients to adjacent coastal waters, and provide a food source directly or indirectly to higher trophic levels. Our approach was to combine experimental studies with river flow data and remote sensing estimates of inundation to determine potential annual areal PP and nutrient release, for the supratidal mudflats in an entire river-estuarine system.

\section{MATERIALS AND METHODS}

There were 4 main components to this study:

- PP, algal biomass and nutrient release were determined experimentally from wetted samples taken from supratidal mudflats across 3 consecutive years.

- Inundation area in the study catchment area was calculated from satellite imagery over 2 wet seasons, and correlated against river height measured at a river gauging station adjacent to the supratidal mudflats. This correlation was used to develop an inundation area model, which predicted the supratidal mudflat inundation area (SMIA) as a function of data on gauged river height, by subtracting the river channel area from the total inundation area.

- The inundation model was then applied to $36 \mathrm{yr}$ of historical gauged river height data to hind cast annual SMIA and duration of inundation.
- Finally, the long-term inundation predictions were combined with the experimental measurements of $\mathrm{PP}$, light attenuation and nutrient release to estimate long-term variability in PP and nutrient release associated with annual inundation patterns.

\section{Study site}

The study site was the tropical supratidal mudflats ('saline supratidal mudflats'; Rhodes 1980), adjacent to the Norman River estuary in the southern Gulf of Carpentaria, Australia (Fig. 1a). The Norman River estuary $\left(17.463^{\circ} \mathrm{S}, 140.82^{\circ} \mathrm{E}\right)$ is a tropical tide-dominated estuary with mean rainfall of $913 \mathrm{~mm}$ (Normanton data, www.bom.gov.au) most of which falls during the summer monsoon period, but is highly
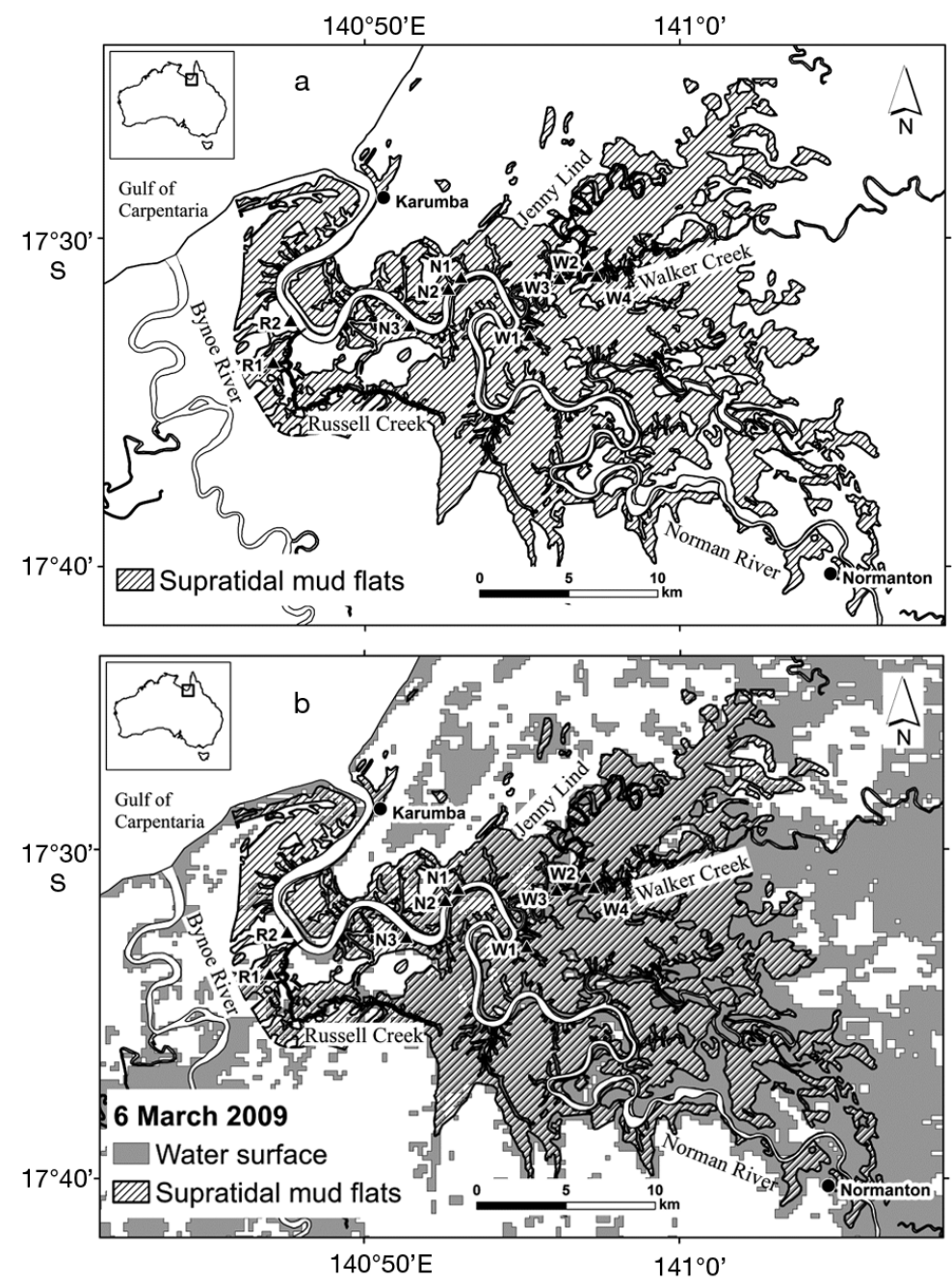

Fig. 1. Sampling sites on the supratidal mudflat adjacent to Walker Creek (W1-W4), Russell Creek (R1-R3) and Norman River (R1 and R2) on the Norman River estuary system, Gulf of Carpentaria, Australia. Supratidal mudflat in (a) the dry season, and (b) during a flood event in 2009 

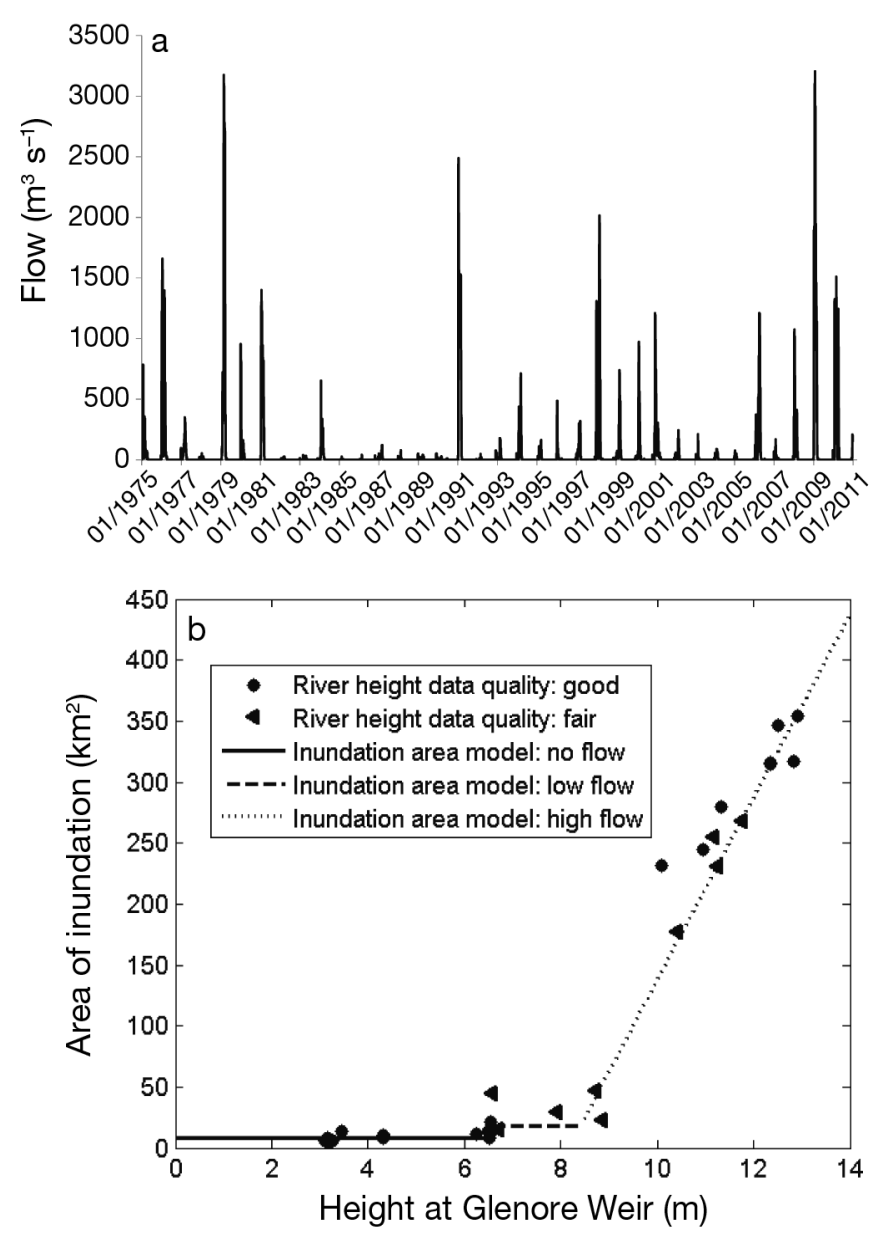

Fig. 2. (a) Hydrograph of river flow rates $\left(\mathrm{m}^{3} \mathrm{~s}^{-1}\right)$ at Glenore Weir gauging station on the Norman River. (b) Relationship between water height $(\mathrm{m})$ measured at Glenore weir and the inundation area $\left(\mathrm{km}^{2}\right)$ in the Norman River catchment estimated from remote sensing

intermittent from year to year (Fig. 2a) (Kennard et al. 2010). During our study, the wet season in Year 1 (2008-2009) had a major flood, while the second wet season (2009-2010) had a moderate flood (Fig. 1b; Duggan et al. 2014).

The estuary has a relatively simple morphology, with a main river channel $\left(36 \mathrm{~km}^{2}\right)$, fringing tidal mudflats, a narrow strip of mangrove forest and beyond this, extensive supratidal mudflats $\left(356 \mathrm{~km}^{2}\right)$ (National Land \& Water Resources Audit 2001; http:// trove.nla.gov.au/people/1306148?c=people). These supratidal mudflats are featureless with a slope as low as $3 \mathrm{~cm} \mathrm{~km}^{-1}$ (Rhodes 1980). In the dry season, the supratidal mudflats have a layer of dried salt. Tidal inundation only affects the supratidal mudflats at the highest astronomical tides, and forms the salt crust upon drying (Rhodes 1980). During annual wet seasons with sufficient rainfall, the supratidal mud- flats are inundated as the high volumes of freshwater flowing downstream flood over the river channel and onto the mudflats, dissolving the salt (Burford et al. 2012). The low slope of the land means that large areas of supratidal mudflat (and terrestrial land) remain inundated with freshwater for days to months. The salt crust re-establishes in the dry season due to residual salt in the sediment, and further accumulates with subsequent high tides and evaporation.

\section{Measurements of productivity and nutrient release}

\section{Sample collection}

Surface soil samples were taken on supratidal mudflats adjacent to the Norman River system towards the end of the dry season in 3 consecutive years. In the first 2 yr (November 2008, November 2009), samples were taken for nutrient release and algal biomass experiments, and in the third year (June 2010) samples were taken for PP measurements. In the first $2 \mathrm{yr}, 6$ sites were sampled, 3 adjacent to the Norman River (N1, N2, N3), 2 adjacent to Russell Creek (R1, R2) and one in Walker Creek (W1) (Fig. 1). All sites had surface soil with similar characteristics, i.e. surface layer of dried salt with fine soil underneath. Two replicate samples of intact soil crust and associated biota were collected at each site, to a depth of 1-2 cm, over a total area of $<5 \mathrm{~m}^{2}$, and carefully placed in clear, shallow plastic trays $(20 \times 27 \times 3$ $\mathrm{cm})$. The trays were stored in a cool dark place until experiments were conducted.

\section{Nutrient release and algal growth experiments}

Nutrient concentrations in the overlying water, and chlorophyll (chl) a concentrations in the soil samples, as a result of inundation of the tray samples, were determined. The trays were filled with distilled water to a depth of $2 \mathrm{~cm}$. Trays were then incubated in direct sunlight. Distilled water was added each day to counteract evaporation. Distilled water was chosen to mimic the freshwater inundating the mudflats during the wet season (Burford et al. 2012). The tray water was subsampled (1 replicate from each of the 3 replicate trays) in Year 1 on Days 1, 2 and 7, and in Year 2 on Days 1, 2, 3, 5, 7 and 9, for dissolved inorganic nutrients (ammonium, nitrate/nitrite, phosphate) by filtering water through a $0.45 \mu \mathrm{m}$ membrane filter, and freezing water samples at $-20^{\circ} \mathrm{C}$ for subsequent analyses. Sediment chl a samples were 
collected in Year 1 on Days 1, 3 and 7, and in Year 2 on Days 2, 4, 6 and 8. Sampling was done by pressing core tubes $(2.4 \mathrm{~cm}$ dia.) randomly into the sediment, collecting the undisturbed top $1 \mathrm{~cm}$ of sediment. Samples were frozen at $-20^{\circ} \mathrm{C}$ until analyzed.

At the end of each experiment, the salinity of the overlying water was determined using a calibrated probe (YSI). In the first experiment, salinity ranged from 44.3 to 107.7 (equivalent to ppt) while in the second experiment it ranged from 37.1 to 118.7. Temperature was also logged hourly (Thermochron iButton) and ranged from $26^{\circ} \mathrm{C}$ at night to a maximum of $46^{\circ} \mathrm{C}$ during the day.

Filtered nutrients were analyzed colorimetrically using standard laboratory methods and a flow injection analyzer (Greenburg et al. 2005). In the laboratory, chl a sediment samples were extracted in acetone using a probe sonicator (Branson 450) and measured spectrophotometrically (Shimadzu) at 665 and $750 \mathrm{~nm}$, pre- and post- acidification to correct for phaeopigments (Jeffrey \& Welshmeyer 1997).

Nutrient and chl a data from the supratidal mudflat experiments were tested for normality and square root transformed before conducting a Pearson's Correlation test (SAS software) to test for correlations between nutrients and chl $a$. Nutrient data from Day 2 was compared with chl a data on Day 3 (no data from Day 2) in the first year, and Day 8 (no data from Days 2 and 3 ) in the second year of experiments. Statistical analyses were also conducted, using an analysis of variance (R software; R Core Team 2015), to test for differences in both nutrient and chl a data between years, sites, and sampling occasions. Data was first tested for normality and log transformed.

To validate the experimental approach used to stimulate algal growth, sediment core samples were also taken for in situ chl a concentrations in soil samples at sites W1, W2, W3, W4 (Fig. 1) after an extended period of flooding in January 2009 and February 2010. Samples were analyzed for chl a using the same protocol as for the experimental samples. Secchi depth readings were done at the same time and used as input for the PP model.

\section{Salinity experiment}

The effect of salinity on benthic algal growth was determined by measuring changes in chl a concentrations in incubations of twenty cores $(4.5 \mathrm{~cm}$ dia. Perspex cores) from one of the sampling sites (W1, Fig. 1). Salinity was measured after inundation of each core, with values ranging from 21.4 to 92.4 . The same protocol was followed as outlined above for incubations of the tray samples.

\section{Primary productivity experiments}

In the third year (June 2010), tray experiments were conducted on soil samples collected from 2 sites, N1 and W4 (Fig. 1), to measure PP and respiration, as determined by oxygen fluxes under a range of light conditions over time. Experiments were conducted with $2 \mathrm{~cm}$ deep samples placed in clear $4.5 \mathrm{~cm}$ dia. Perspex cores, filled with deionized water and covered with clear plastic film to prevent evaporation losses. Cores were placed in a water bath set at a temperature of $30^{\circ} \mathrm{C}$ in direct sunlight. There were 5 light treatments: 100, 10, 1 and $0.5 \%$ sunlight and dark, with 4 replicates for each treatment. Neutral density filter sheets were used to create the appropriate light levels (Burford et al. 2012). Additionally, there were 2 controls, containing only deionized water and no soil. Oxygen production/consumption rates were quantified by measuring changes in the dissolved oxygen (DO) concentrations in the water overlying each core hourly over $5 \mathrm{~h}$ each morning for a total of $11 \mathrm{~d}$ under a diel cycle. DO was measured using a PreSens Microx TX3 and oxygen microsensor (PreSens Precision Sensing). Ambient light measurements were logged using the PAR light sensor (Licor LI-1400). Oxygen production and consumption rates, as $\mathrm{mg} \mathrm{O}_{2} \mathrm{l}^{-1} \mathrm{~h}^{-1}$, were calculated using a linear regression of DO vs. time. The volume was converted to the areal productivity and respiration based on the water volume, and surface area of the sediment in the core incubators. It was assumed that there was sufficient sunlight for PP for $10 \mathrm{~h} \mathrm{~d}^{-1}$. Oxygen was converted to $\mathrm{C}$ based on a molar conversion ratio of 1:1. Analysis of variance testing was also conducted on log-transformed PP data using R software (R Core Team 2015) to test for differences between sites and light levels.

\section{Inundation model development}

An inundation model was constructed to predict SMIA as a function of daily river height measured at a gauging station situated at an overflow weir (Glenore Weir, $80 \mathrm{~km}$ from the mouth of the Norman River estuary; www.derm.qld.gov.au/water). The model was developed by quantifying the relationship between the water height at the river gauging station with total inundation area as calculated from satellite 
images over the period October 2008 to 30 April 2010. The inundation model was then applied to predict annual inundation characteristics (including maximum area, depth and duration) based on gauging station data from 1975-2010. River channel area was subtracted from total inundation area to determine the SMIA.

Remote sensing to determine inundation area

Satellite imagery was used to estimate total inundation area within the Norman River catchment for 32 largely cloud-free images collected between 21 October 2008 and 30 April 2010, i.e. over the 2 wet seasons of the study. Area of land inundated by water was calculated from the MODIS Level 1B Calibrated Geolocation Data Set, which had pixel values converted to radiance. To maximize the resolution of the flood delineation, only MODIS $250 \mathrm{~m}$ resolution RED (band 1) and NIR (near infrared) (band 2) bands were used for image classification.

Spectral metrics, such as band ratios and difference indices using near infrared (NIR) spectral data $(>800 \mathrm{~nm})$, are commonly employed for delineating water features (McFeeters 1996, Frazier \& Page 2000, Davranche et al. 2010). For this study, the Normalised Difference Vegetation Index (NDVI) and the NIR band were used to identify the extent of flood water. NDVI is calculated as NDVI $=(\mathrm{NIR}-\mathrm{RED}) /(\mathrm{NIR}+$ RED) and is commonly applied as an indicator of live green vegetation (Defries \& Townshend 1994). Free standing water has low reflectance in MODIS bands 1 and 2, and values of NDVI close to zero are indicative of water features and can be applied to delineate flood waters from surrounding land (Davranche et al. 2010, Ward et al. 2013).

Images were cropped to the broad region of interest (southern Gulf of Carpentaria). Histogram density slicing (Frazier \& Page 2000) was applied to the NDIV and NIR data to delineate flood water. Densityslicing thresholds varied between images, and were manually checked against the coastline location to ensure that marine water was correctly delineated from terrestrial land. Images were then cropped to the Norman River catchment. Area of inundation was estimated as the area of pixels with NDVI less than the critical density slicing threshold. The same process was repeated using NIR for cross-validation. Local information (e.g. timing and duration of road closure due to flooding and discharge volume at Glenore Weir) was used to ground-truth the inundation area calculated from remote sensing. While all efforts were made to eliminate cloud cover, some images were processed with sparse cloud cover which was masked out and not included in image analysis.

The supratidal mudflat extent within the Norman catchment was defined using the Geoscience Australia 2006 GEODATA 250k topographic mapping (www.ga.gov.au/). The 'Saline Coastal Flat' feature class was used to delineate the supratidal mudflat extent with the addition of some $4 \%$ of the area comprising 'Swamp', and 'Land Subject to Inundation' classes that were either mislabeled or had changed since the original mapping in the late 1970s. The boundary of the supratidal mudflat extent was defined by the Norman river catchment boundary to the west. However, 2 tidal creeks occurred between the supratidal mudflat extent and the Norman river catchment boundary to the north east. Consequently, drainage lines and direction associated with the tidal creeks was used to define the north eastern boundary of the supratidal mudflat study area extent. The delineated total flood extent (including non-SMIA floodplains) for the Norman catchment was then 'clipped' to the supratidal mudflat study area extent for the inundation area model.

\section{Correlating inundation area to gauged river height}

Daily river height data is available for Glenore Weir (www.derm.qld.gov.au/water). The Department of Natural Resources and Mines designated the river height data quality in 3 categories: good; fair; poor; or estimate. Only good and fair data was used in the study (Fig. 2b).

The height of the Glenore weir was $6.4 \mathrm{~m}$, meaning that when the water height was above $6.4 \mathrm{~m}$, water was flowing over the weir. Between water heights of 6.5 and $8.4 \mathrm{~m}$, flow was contained within the downstream river channel (www.derm.qld.gov.au/water). Above $8.4 \mathrm{~m}$ water height, the river was no longer contained in the channel. These river heights were therefore used to define 3 flow regimes at Glenore Weir: no $(<6.5 \mathrm{~m})$, low $(6.5-8.4 \mathrm{~m})$ and high flow $(>8.4 \mathrm{~m})$. Supratidal mudflat inundation was the area inundated, excluding the area of the river channel.

Estimated inundation area for 31 January 2012 was excluded from the analysis as an outlier, because despite the high flow through Glenore Weir (772-1030 $\mathrm{m}^{3} \mathrm{~s}^{-1}$ flow, $10.2-10.9 \mathrm{~m}$ height) over that day, the floodplain area of inundation was low. The source of this anomaly is not known, but it may relate to the timing of the satellite. 
Long-term estimates of annual inundation

The inundation area model was applied to the river height gauge at Glenore Weir for the total period for which river height records are available, i.e. 1 July 1975 to 30 June 2012 (Fig. 2b). Data were integrated into an annual timestep based on water years, i.e. July to June, to capture the entire wet season in the austral summer (December to March) each year. The inundation area model was used to estimate the maximum area of floodplain inundated per year and was coupled with the data from experimental studies to determine nutrient release and PP.

For $\mathrm{PP}$, the depth distribution of the inundated area and light attenuation with water depth in situ were both used. Secchi depth, as a measure of light attenuation through the water, was measured as $0.2-0.3 \mathrm{~m}$ on the inundated supratidal mudflats in January 2009 and February 2010. The average of these 2 Secchi depths was used to calculate the light attenuation coefficient (Chapra 1997).

\section{RESULTS}

\section{Measurements of productivity and nutrient release}

Ammonium, nitrate/nitrite and phosphate concentrations were measured in the overlying water after wetting the supratidal mudflat samples. Overall, ammonium concentrations were significantly higher in Year 1 than Year 2 ( $p<0.005)$; conversely, nitrate/nitrite and phosphate concentrations were significantly higher in Year 2 than Year 1 ( $<$ 0.05) (Fig. 3). In Year 1, ammonium, nitrate/nitrite and phosphate concentrations were highest on Day 2 ( $\mathrm{p}<0.05)$. In Year 2, there were more sampling days (Days 1, 2, 3, 5, 7, 9). Nitrate/nitrite leaching were highest early in the experiment; being statistically higher $(\mathrm{p}<0.05)$ on Days 1,2 and 3 compared with Day 9, while ammonium was statistically higher $(\mathrm{p}<0.05)$ on Days 3 and 5 compared with all other days. Phosphate concentrations were highest later in the experiment, although there was no consistency in statistical differences between days. There

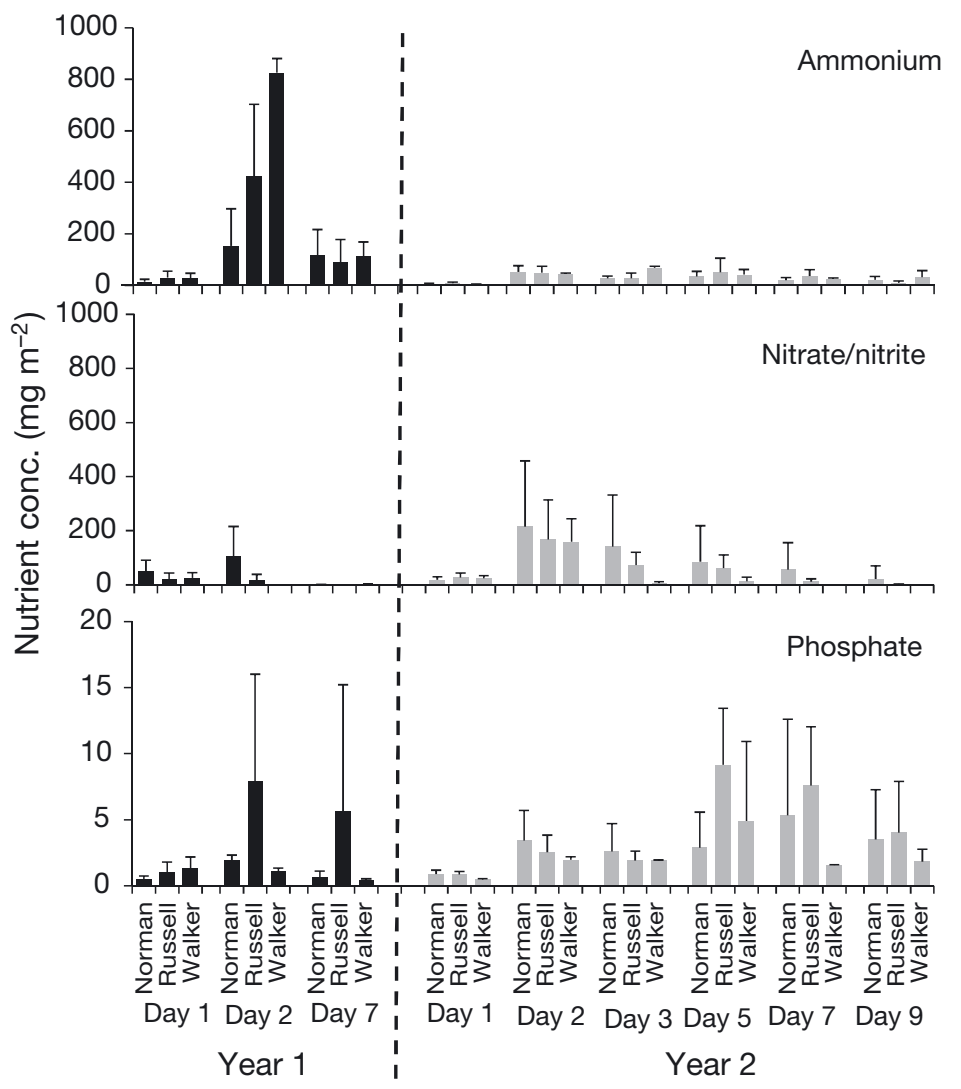

Fig. 3. Mean (+SD) ammonium, nitrate/nitrite and phosphate concentrations $\left(\mathrm{mg} \mathrm{m}^{-2}\right)$ in water overlying sediments in tray experiments versus duration of inundation. Means were calculated from multiple trays in sites within supratidal mudflats adjacent to Russell (R1, R2) and Walker Creeks (W1), and the Norman River (N1, N2, N3; see Fig. 1 for site locations) for consecutive days in 2008/09 and 2009/10

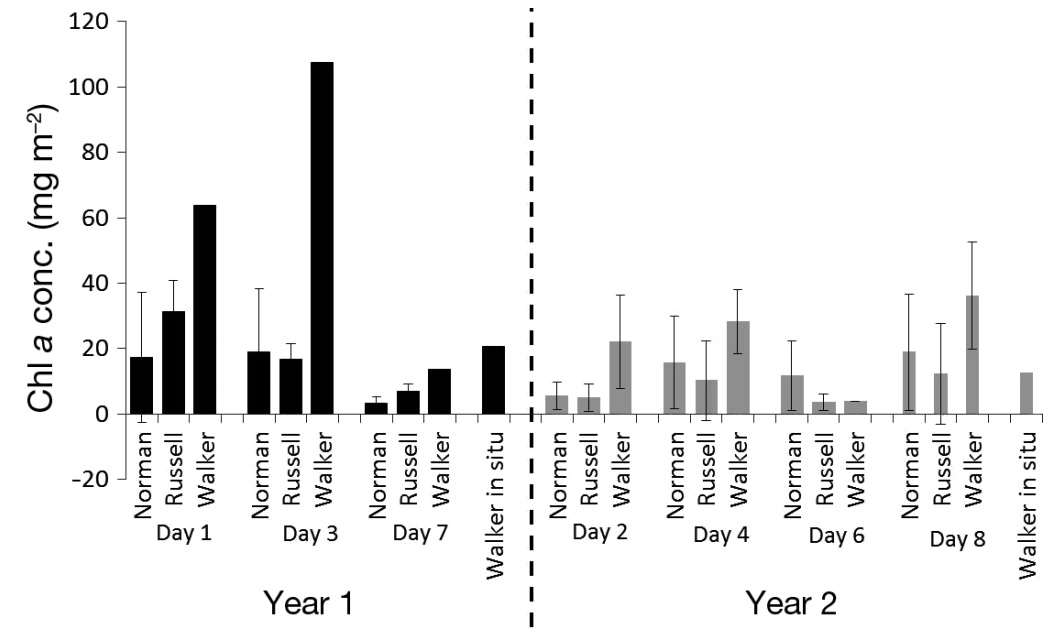

Fig. 4. Mean $( \pm \mathrm{SD})$ chlorophyll (chl) a concentrations $\left(\mathrm{mg} \mathrm{m}^{-2}\right)$ in sediments inundated for consecutive days in 2008/09 and 2009/10 during incubations. Samples were collected from supratidal mudflats adjacent to Russell and Walker Creeks, and the Norman River sites (see Fig. 1 for site locations). Additionally, in situ samples were collected from sites on Walker Creek during inundation for comparison with the experimental results 
were no statistically significant differences between sampling sites within each year.

There were statistically significant differences in chl a concentrations between years $(p<0.01)$, but not between sites or sampling occasions (Fig. 4). The destructive sampling method means that even though sampling through time occurred within a small area $\left(0.054 \mathrm{~m}^{2}\right)$, high spatial heterogeneity in the soil could not be avoided. Microscopic examination of samples revealed that the dominant benthic algal genera in the samples were the cyanobacteria Oscillatoria spp., Geitlerinema spp., and Phormidium spp. In a separate experiment using samples from one site, it was determined that there was no significant correlation between salinity (ranging from 21.4 to 92.4) in the water column and chl a concentrations in the sediment $\left(r^{2}=0.02, p>0.05\right)$.

Maximum chl a concentrations, i.e. Day 3 in Year 1, and Day 8 in Year 2, were compared with nutrient concentrations in the overlying water for the same days. Chl a was significantly and positively correlated with ammonium concentrations $\left(\mathrm{r}^{2}=0.64\right)$ but negatively correlated with nitrate/nitrite concentrations $\left(\mathrm{r}^{2}=-0.49\right)$ (Table 1$)$. There was no significant correlation between chl $a$ and phosphate concentrations.

Table 1. Correlation between sediment chlorophyll (chl) a concentrations (measured on Day 3 in Year 1, Day 8 in Year 2), and nutrient concentrations (measured on Day 2 in both years) across multiple Norman River, Russell and Walker Creek sites (see Fig. 1) during supratidal mudflat inundation tray experiments $(\mathrm{n}=12) .{ }^{*} \mathrm{p}<0.05,{ }^{* * *} \mathrm{p}<0.005$

\begin{tabular}{|lccc|}
\hline Parameter & Ammonium & $\begin{array}{c}\text { Nitrate/ } \\
\text { nitrite }\end{array}$ & Phosphate \\
\hline Chl $a$ & $\mathbf{0 . 6 4}^{\text {*** }}$ & $\mathbf{- 0 . 4 9 *}^{*}$ & -0.32 \\
Ammonium & - & $\mathbf{0 . 4 5}^{*}$ & -0.12 \\
Nitrate/nitrite & - & - & $\mathbf{0 . 4 1}^{*}$ \\
\hline
\end{tabular}

Table 2. Supratidal mudflat inundation area (SMIA) of the Norman River as a function of river height at Glenmore Weir ( $h$, in metres) and associated flow regime

\begin{tabular}{|c|c|c|c|}
\hline$h(\mathrm{~m})$ & Flow regime & $\begin{array}{l}\text { Total inundation } \\
\text { area }\left(\mathrm{km}^{2}\right)\end{array}$ & SMIA $\left(\mathrm{km}^{2}\right)$ \\
\hline$<6.5$ & No flow over weir & $\begin{array}{c}8 \pm 3 \\
\text { (river channel only) }\end{array}$ & 0 \\
\hline $6.5-8.4$ & Low flow & $\begin{array}{c}18 \pm 6 \\
\text { (river channel only) }\end{array}$ & 0 \\
\hline$>8.5$ & High flow & $\begin{array}{c}\mathrm{a} h-\mathrm{b} \\
\text { where } \mathrm{a}=75 \pm 10 \mathrm{~km}^{2} \mathrm{~m}^{-1} \\
\mathrm{~b}=613 \pm 114 \mathrm{~km}^{2} \\
\text { (river channel and flood plain) }\end{array}$ & $75 \times(h-8.4)$ \\
\hline
\end{tabular}

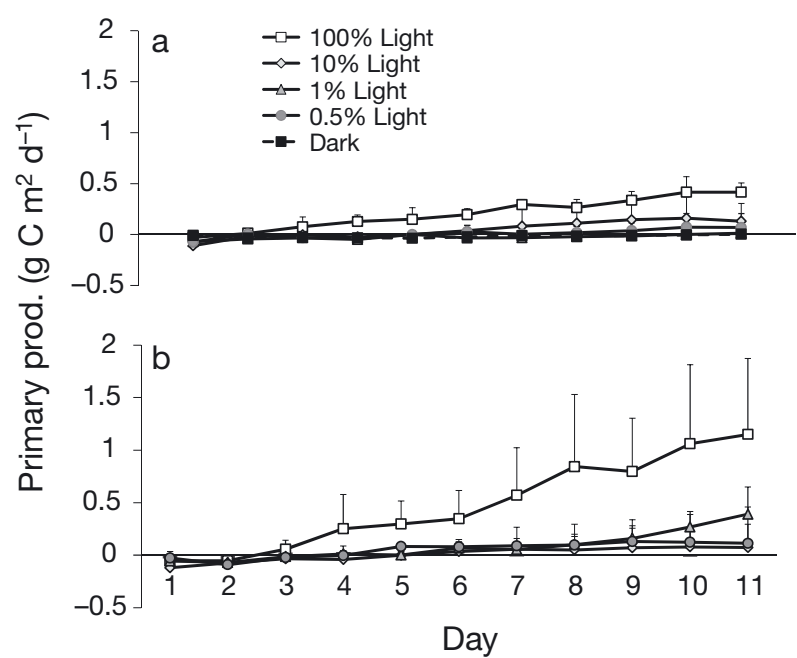

Fig. 5. Mean (+SD) primary productivity rates $\left(\mathrm{g} \mathrm{C} \mathrm{m}^{-2} \mathrm{~d}^{-1}\right)$ for supratidal sediments collected at (a) Site W4 near Walker Creek, and (b) Site N1 near the Norman River after continuous artificial inundation and exposure to a range of light levels on a diel cycle over $11 \mathrm{~d}$

Ammonium and nitrate/nitrite concentrations were negatively correlated $\left(r^{2}=-0.45\right)$ while nitrate/nitrite and phosphate concentrations were positively correlated $\left(\mathrm{r}^{2}=0.41\right)$ (Table 1$)$. In addition, chl a concentrations in situ during the wet season inundation in both years were found to be comparable with those in our experiment with artificial inundation (Fig. 4).

PP in the supratidal mudflat samples, as estimated from oxygen flux experiments, increased over the $11 \mathrm{~d}$ of the incubation study (Fig. 5). By Day 11, Site W4 had statistically higher productivity in $100 \%$ light than in 1 or $0.5 \%$ light $(\mathrm{p}<0.05)$. In contrast, the high variability in replicate samples from Site N1 meant that there was no significant difference between light levels on Day 11 in samples. There was no significant difference between the 2 sites at $100 \%$ light on Day 11. Respiration reached a maximum by Day 1 for the dark treatments and ranged from 41.4 to $139.4 \mathrm{mg} \mathrm{C} \mathrm{m}^{-2} \mathrm{~d}^{-1}$.

\section{Inundation model}

The inundation area calculated from satellite imagery was strongly related to river height. For the high flow regime, the area inundated varied linearly with height of the river at Glenore Weir $(p<0.001)$ (Fig. 2b). The SMIA was therefore also a function of height at Glenore weir, and the equations are shown in Table 2. 
Each additional $10 \mathrm{~cm}$ of river height at Glenore Weir when the river leaves the channel (i.e. at depths above $8.4 \mathrm{~m}$ ) corresponds to a $7.5 \mathrm{~km}^{2}$ increase in area of floodplain inundation. Hence if we assume a simple 'bathtub' model for bathymetry (which is not unreasonable given the very low vertical relief of the area), then the maximum depth of the floodplain $\left(h_{\max }\right)$ will be the difference between the river height at Glenore Weir, and the weir height $(8.4 \mathrm{~m})$.

Based on this model, a river height $(h)$ of 9 m measured at Glenore Weir would correspond to an inundated area of SMIA $=45 \mathrm{~km}^{2}$ and maximum water depth of $h_{\max }=60 \mathrm{~cm}$, with approximately $7.5 \mathrm{~km}^{2}$ of increased inundation at each water depth increment of $10 \mathrm{~cm}$.

\section{Model results}

Total nutrient loads for each year were calculated based on the model of inundation area of supratidal mudflats combined with the experimental data for minimum and maximum values for nutrient concentrations in the overlying water of mudflats on the day (Table 3). Nutrient concentrations were highly variable between years and on the sampling days but Day 2 was chosen as there was data from this day for

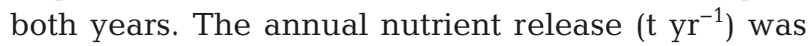
hence calculated as:

$$
\mathrm{ANR}=\mathrm{ANF} \times \mathrm{SMIA}_{2 \mathrm{~d} \max }
$$

where ANR is the annual nutrient release from the supratidal mudflats, ANF is the areal nutrient flux determined from the experimental studies, and $\mathrm{SMIA}_{2 \mathrm{~d} \text { max }}$ is the maximum SMIA which has been inundated for at least 2 consecutive days within the given year. Nutrient release rates where highly variable, so annual nutrient release was calculated from the data for both low and high nutrient release scenarios (Table 3).

Based on the model output, there is high interannual variability in the calculated mass of nutrients released from the supratidal mudflats, driven by the size of the flood event (Fig. 6). Maximum and minimum values ranged considerably for ammonium and nitrate/nitrite, based on the experimental results. Here was less variation for phosphate. Highest annual values of release were 166, 64 and $1.3 \mathrm{t}$ for ammonium, nitrate/nitrite and phosphate respectively.

The experimental studies showed that benthic PP was affected by light levels (although only statistically significant for one of the 2 sites used in the experimental studies). However, modelling productivity based on light was not feasible, due to the uncertainty and variability in water clarity, and the inherent errors associated with such a simplistic model for depth distribution. Instead we used the average productivity (within the euphotic zone) recorded on Days 5 and 10 in the experimental studies, and assumed that this approximated the benthic productivity for inundated supratidal mudflats where at least $1 \%$ of light penetrated to the sediment (Table 3 ).

Five days was chosen as the minimum duration for initiating benthic productivity in the experiments. The effect of $10 \mathrm{~d}$ inundation was also chosen, based on the experimental data, to compare with $5 \mathrm{~d}$ and

Table 3. Parameters and rates used for nutrient and $\mathrm{C}$ model based on mean values on Day 2 for nutrients, and Days 5 and 10 for primary productivity ( $\left.\mathrm{PP} ; \mathrm{mg} \mathrm{C} \mathrm{m}^{-2} \mathrm{~h}^{-1}\right)$. ANF: areal nutrient flux $\left(\mathrm{mg} \mathrm{m}^{-2}\right)$; CPI: critical period of inundation

\begin{tabular}{|c|c|c|c|}
\hline Process & Scenario & Source & Inundation model \\
\hline $\begin{array}{l}\text { Ammonium ANF } \\
\text { from sediment }\end{array}$ & $\begin{array}{l}\text { Low: } 48 \\
\text { High: } 468\end{array}$ & $\begin{array}{l}\text { Tray incubations, multiple sites } \\
\text { and replicates, } 2 \text { yr }\end{array}$ & \multirow{3}{*}{$\begin{array}{l}\text { - } \mathrm{SMIA}_{2 \mathrm{~d} \text { max }} \text { maximum area of } \\
\text { supratidal mudflats inundated for } \\
\text { at least } 2 \text { consecutive days } \\
\text { - Nutrients released no more } \\
\text { than once per wet season }\end{array}$} \\
\hline $\begin{array}{l}\text { Nitrate/nitrite ANF } \\
\text { from sediment }\end{array}$ & $\begin{array}{l}\text { Low: } 41 \\
\text { High: } 180\end{array}$ & $\begin{array}{l}\text { Tray incubations, multiple sites } \\
\text { and replicates, } 2 \text { yr }\end{array}$ & \\
\hline $\begin{array}{l}\text { Phosphate ANF from } \\
\text { sediment }\end{array}$ & $\begin{array}{l}\text { Low: } 2.6 \\
\text { High: } 3.6\end{array}$ & $\begin{array}{l}\text { Tray incubations, multiple sites } \\
\text { and replicates, } 2 \text { yr }\end{array}$ & \\
\hline Benthic PP & $\begin{array}{c}\mathrm{CPI}=5 \mathrm{~d}, \mathrm{PP}_{5 \mathrm{~d}}=11 \\
\mathrm{CPI}=10 \mathrm{~d}, \mathrm{PP}_{10 \mathrm{~d}}=43\end{array}$ & $\begin{array}{l}\text { PP rates measured in core incu- } \\
\text { bation experiments, at a range of } \\
\text { light levels, on Days } 5 \text { and } 10 \text { of } \\
\text { inundation }\end{array}$ & $\begin{array}{l}\text { - } \mathrm{SMIA}_{\mathrm{N} \text { euphotic: }} \text { area of supratidal } \\
\text { mudflats inundated for at least } \\
\mathrm{N}=5 \text { or } 10 \text { consecutive days, } \\
\text { integrated over the year CPI } \\
\text { - Mean PP rates measured at } 1 \text { and } \\
100 \% \text { light for } \mathrm{N}=5 \text { or } 10 \mathrm{~d} \text { used } \\
\text { for calculations }\end{array}$ \\
\hline
\end{tabular}




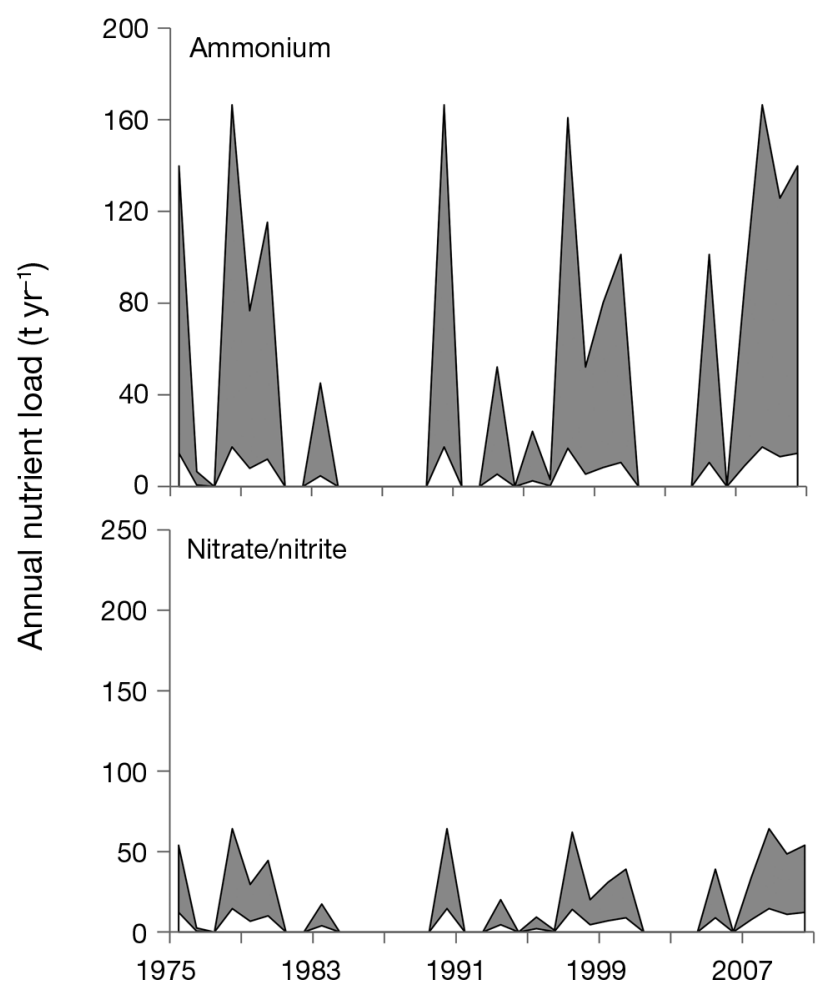

highlight the critical nature of inundation period in annual estimates. Therefore in estimating supratidal mudflat productivity, we ran the inundation model for two scenarios: productivity based on 5 and $10 \mathrm{~d}$ inundation respectively. The annual benthic productivity was calculated as follows:

$$
\mathrm{ABP}_{\mathrm{N}}=\mathrm{PP}_{\mathrm{N}} \times \mathrm{SMIA}_{\mathrm{N} \text { euphotic }}
$$

where $\mathrm{ABP}_{\mathrm{N}}$ is annual benthic productivity, based on 5 or $10 \mathrm{~d}$ inundation, $\mathrm{PP}_{\mathrm{N}}$ is areal primary productivity rate determined experimentally on Day $\mathrm{N}=5$ or 10 , and $\mathrm{SMIA}_{\mathrm{N} \text { euphotic }}$ is the area of supratidal mudflats within the euphotic zone which has been inundated for more than 5 or $10 \mathrm{~d}$ respectively, integrated over the year. Soil is assumed to be dry if uncovered by water for $>2 \mathrm{~d}$.

Using Eq. (2), algal production was calculated for the whole Norman River supratidal mudflat system $\left(356 \mathrm{~km}^{2}\right)$ using the mean of rates measured at 1 and $100 \%$ of surface light on Days 5 and 10 of the experiment, and a mean of 2 measured Secchi depths, 0.2 and $0.3 \mathrm{~m}$ in situ. Annual benthic algal production ranged between $0 \mathrm{t} \mathrm{C}$ in dry years up to $377 \mathrm{t} \mathrm{C}$ for the most productive years, provided there was a minimum of $5 \mathrm{~d}$ inundation (Fig. 7). For $10 \mathrm{~d}$ inundation period, maximum annual production was $273 \mathrm{t} C$. This value was lower than $5 \mathrm{~d}$ inundation because the probability of inundation for a longer period was lower.

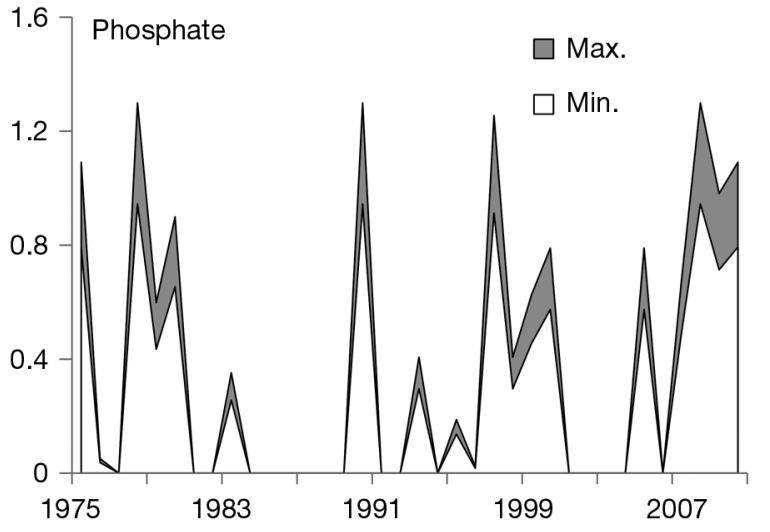

Fig. 6. Calculated range of potential annual loads $\left(\mathrm{t} \mathrm{yr}^{-1}\right)$ of ammonium, nitrate/nitrite and phosphate released from supratidal mudflats into overlying water based on the estimated areal inundation of the Norman River after a minimum of $2 \mathrm{~d}$ consecutive inundation, for low and high release scenarios (Table 3 ). Note: years with no peaks are years with no inundation of supratidal mudflats

\section{DISCUSSION}

This study showed that, after $48 \mathrm{~h}$ of inundation, there was substantial nutrient accumulation in overlying waters from seasonally inundated supratidal mudflats. However there was considerable variabil-

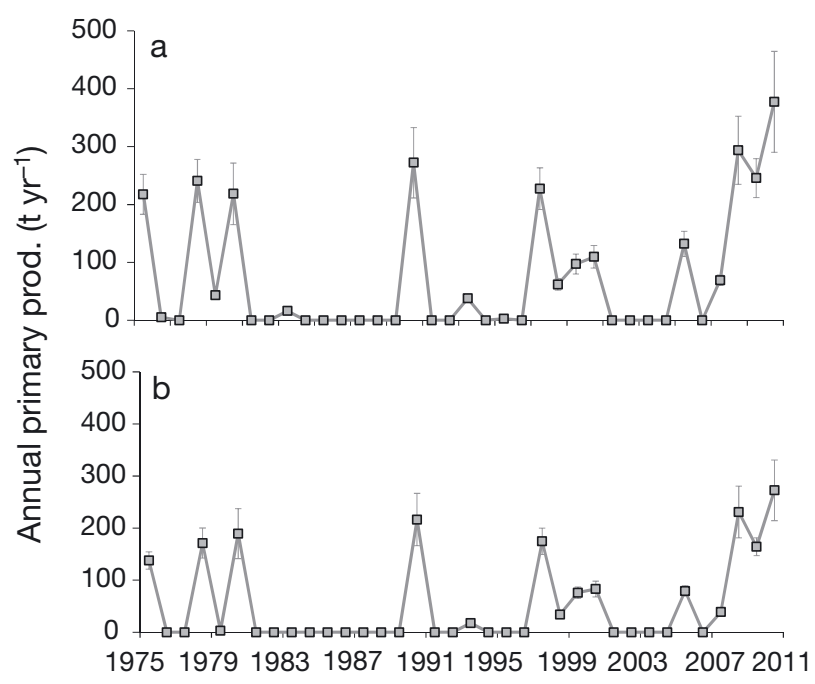

Fig. 7. Mean primary production $( \pm \mathrm{SD})\left(\mathrm{t} \mathrm{C} \mathrm{yr}^{-1}\right)$ based on the estimated areal inundation of the Norman River supratidal mudflat after (a) $5 \mathrm{~d}$ and (b) $10 \mathrm{~d}$ consecutive inundation. Mean value was calculated based on 2 scenarios of 0.2 and $0.3 \mathrm{~m}$ Secchi depth using the mean productivity at 1 and $100 \%$ light conditions in controlled experiments. Note: years with no peaks are years with no inundation of supratidal mudflats 
ity between replicates, sites and years. This reflects the heterogeneity of the soil, and the observed fluctuations in topology as a result of sediment scouring and deposition during previous inundation events. The model output from our study also showed that there was a high level of interannual variability in released nutrients driven mostly by differences in inundation area between years. In a number of years, the lack of inundation resulted in no nutrient release.

The slow release of nutrients in our study contrasts with a study of tidally inundated cyanobacterial mats growing behind mangroves in a subtropical embayment, which had maximum release of phosphate, ammonium and nitrate after $1 \mathrm{~h}$ (Paling \& McComb 1994). Additionally, the rates of release in their study were substantially lower (1 to 2 orders of magnitude) than in our study. However, these mats were inundated more frequently than those in our study, meaning that soil moisture and associated microbial activity at the time of inundation was initially likely to be higher, and nutrient reserves lower. Additionally, the standing stocks of cyanobacteria may also remain higher in their study since the mats do not become completely desiccated between inundation events.

Our study showed that PP on inundated supratidal mudflats in a wet-dry tropical system has the potential to be a significant contributor to primary production in coastal areas (up to an estimated $377 \mathrm{t} \mathrm{C}$ annual productivity in the Norman River supratidal mudflat system). However, primary production across the supratidal mudflats varied substantially from year to year, driven mostly by the scale of inundation during the wet season. In the study, there were multiple years with little or no inundation, e.g. $2001 / 02$ to $2004 / 05$, resulting in no calculated primary production. Therefore, the supratidal mudflats are highly dynamic systems both in the short and long term, with productivity driven in large part by the magnitude and duration of wet season flooding. Nutrient release from the mudflats is likely to be related to senescence and subsequent degradation of benthic algae from the previous season. As such, the scale of inundation from the previous year, and associated benthic algal growth, may affect nutrient release in the subsequent year.

The estimated annual PP rate and chl a concentrations of the supratidal mudflats were compared with results from previous studies in the same estuary for phytoplankton and benthic algae on intertidal mudflats (Table 4). Chl a concentrations on the intertidal mudflats were highest, i.e. $22.5-44.5 \mathrm{mg} \mathrm{m}^{-2}$, followed by the supratidal mudflats (when inundated), i.e. $19.8 \mathrm{mg} \mathrm{m}^{-2}$, then phytoplankton $9.2-19.2 \mathrm{mg} \mathrm{m}^{-2}$ (Burford et al. 2012, Duggan et al. 2014). PP per unit area was similar between the 3 habitats when supratidal mudflats in the wet season were compared with intertidal mudflats and phytoplankton in the dry season.

However, on an annual whole-system basis within the estuary, phytoplankton had the highest contribution to PP rates, i.e. $72-83 \%$, compared to tidal mudflats, i.e. $15-17 \%$. Supratidal mudflats ranged from $0 \%$ contribution in years with no inundation, to $13 \%$ of the total in years with inundation. However, while productivity on the supratidal mudflats only occurred in the wet season, most production in the intertidal mudflats and phytoplankton occurred in the dry season. Our figures are likely to be underestimates of the contribution of supratidal mudflats since our modelling was based on PP incubations which were only conducted for $11 \mathrm{~d}$. Rates may have increased with longer periods of inundation, however, the frequency of longer term inundation per year would also decrease.

A study by Lovelock et al. (2010) measured PP rates of 26.6-95.6 $\mathrm{mg} \mathrm{C} \mathrm{m}^{-2} \mathrm{~h}^{-1}$ on tidal and supratidal flats in the arid subtropics of Western Australia, which were similar to our areal rates, i.e. $42.0-105.6 \mathrm{mg} \mathrm{C}$ $\mathrm{m}^{-2} \mathrm{~h}^{-1}$. However, chl a concentrations were higher in their study than ours, i.e. $224-416 \mathrm{mg} \mathrm{m}^{-2}$ compared with 1.3-107.4 $\mathrm{mg} \mathrm{m}^{-2}$, respectively. A key difference between the studies was that the mudflats in

Table 4. Comparisons of chlorophyll (chl) a concentrations $\left(\mathrm{mg} \mathrm{m}^{-2}\right)$, and areal and whole-system primary productivity (PP, mg $\mathrm{C} \mathrm{m}^{-2} \mathrm{~h}^{-1}$ and tonnes $\mathrm{C}$ per season) in the supratidal mudflat and adjacent intertidal mudflats and estuarine water of the Norman River system. Whole-system PP refers to the combination of estuary, supratidal and intertidal mudflats. Wet: wet season; dry: dry season. Note: mangroves are not included as there is insufficient data

\begin{tabular}{|c|c|c|c|c|c|c|c|c|c|}
\hline \multirow[t]{2}{*}{ Habitat } & \multirow[t]{2}{*}{$\begin{array}{c}\text { Area } \\
\left(\mathrm{km}^{2}\right)\end{array}$} & \multicolumn{2}{|c|}{$\begin{array}{c}\mathrm{Chl} \mathrm{a} \\
\left(\mathrm{mg} \mathrm{m}^{-2}\right)\end{array}$} & \multicolumn{2}{|c|}{$\begin{array}{c}\text { Areal PP } \\
\left(\mathrm{mg} \mathrm{C} \mathrm{m}^{-2} \mathrm{~h}^{-1}\right)\end{array}$} & \multicolumn{2}{|c|}{$\begin{array}{l}\text { Whole-system PP } \\
\text { (t C per season) }\end{array}$} & \multirow{2}{*}{$\begin{array}{l}\text { Annual contri- } \\
\text { bution to whole- } \\
\text { system PP (\%) }\end{array}$} & \multirow[t]{2}{*}{ Reference } \\
\hline & & Wet & Dry & Wet & Dry & Wet & Dry & & \\
\hline Supratidal mudflat & 356 & 19.8 & nd & 43 & 0 & $0-377$ & 0 & $0-13$ & This study \\
\hline Intertidal mudflat & 1 & 22.5 & 44.5 & 0 & 54 & 0 & 145 & $15-17$ & Duggan et al. (2014) \\
\hline Phytoplankton & 8 & 9.2 & 19.2 & 14 & 41 & 27 & 703 & $72-83$ & Burford et al. (2012) \\
\hline
\end{tabular}


their study were inundated more frequently than those in our study, meaning that the algal species in their study were likely to be more highly adapted to a rapid response to inundation. It took approximately $3 \mathrm{~d}$ for PP to commence in our study.

Paling et al. (1989) also found higher chl a concentrations of $50-150 \mathrm{mg} \mathrm{m}^{-2}$ for cyanobacterial mats in the Dampier Archipelago. They estimated that cyanobacterial mats contributed $5-15 \%$ of the total C fixed by primary producers in the entire coastal system. Lovelock et al. (2010) proposed that a significant proportion of the production by cyanobacteria on mudflats is allocated to extracellular carbohydrates which are released upon wetting. This in turn fuels the microbial community. It is likely that this mechanism is also occurring in our study, as microbial activity occurred very quickly after wetting of sediment, as indicated by the respiration rates of $41.4-139.4 \mathrm{mg}$ $\mathrm{C} \mathrm{m}^{-2} \mathrm{~d}^{-1}$ and net heterotrophic production in the first few days.

Our study found that a salinity ranging from 21 to 92 had no effect on chl a concentration. Therefore the benthic algal community appears to be highly adapted to high and variable salinities. Conversely, Kirkwood \& Henley (2006) found a trend of declining chl $a$ as salinity increased, although the salinity in their study was much higher, i.e. up to 350 in algal communities in a terrestrial hypersaline environment (Great Salt Plains, USA).

Ammonium had a strong positive correlation with chl a concentrations. One interpretation of this is that nitrogen is a limiting nutrient for benthic algae, and the ammonium is being rapidly assimilated. Ammonium is the form of nitrogen most easily assimilated by algae (Raven 1984, Dortch 1990), and can be released via desorption from soil, or from organic matter upon rewetting. Nitrate was negatively correlated with chl a concentrations, suggesting that nitrate was not the important source of nitrogen for benthic algal growth. Nitrate is often loosely bound to soil and released after rewetting. Understanding the sediment biogeochemistry as a result of wetting and drying and fluctuating salinity in these environments warrants more research.

The stoichiometric molar C:nitrogen ratio for algae (6.6:1; Redfield 1958) was also used to determine nitrogen requirements, calculated from measured areal rates of PP. This was compared with the total measured dissolved inorganic nitrogen released from the supratidal mudflats after wetting. Based on these calculations, dissolved inorganic nitrogen release from wetting only provides $2.9-6.6 \mathrm{~d}$ of nitrogen requirements for the benthic algae. This supports the argu- ment for nitrogen limitation on the supratidal mudflats. Kirkwood \& Henley (2006) also found that ammonium concentrations were an important predictor of algal biomass in a terrestrial hypersaline environment as did studies of cyanobacterial mats in the arid subtropics (Paling et al. 1989, Lovelock et al. 2010, Adame et al. 2012). The nitrogen:phosphorus ratios of the dissolved nutrients were much higher than Redfield (1958) ratios, which suggests that phosphorus, as well as nitrogen availability may also limit production, although the relatively high phosphate levels appear to discount this.

Nitrogen has been shown to be a key limiting nutrient in studies of the Norman River estuary, and the Gulf of Carpentaria as a whole (Burford et al. 2009, 2012). Total calculated nitrogen and phosphorus loads in freshwater discharged from the Norman River over the wet season were 4300 and $800 \mathrm{t}$ respectively in 2008/09, and 2500 and 400 t respectively in 2009/2010 (Burford et al. 2012). Therefore river discharge provides an important nitrogen source to coastal areas in years where discharge occurs. Annual modelled nitrogen and phosphorus release across the supratidal mudflats in those years, assuming a minimum of $2 \mathrm{~d}$ of inundation, was approximately $1-8 \%$ and $<1 \%$ of the total nitrogen and phosphorus discharge loads respectively for the river system across both years. Given the calculated nitrogen requirements of benthic algae on the supratidal mudflats, it cannot be assumed that all nitrogen is discharged into the river; mudflats may actually be a net sink for nitrogen. However, in a creek within the Norman River estuary, Ridd et al. (1988) found higher dissolved phosphate and nitrate/nitrite concentrations from water running off the supratidal mudflat on the ebb tide compared with the adjacent river. It is clear that further research on the sources, transformations and fate of nutrients in these supratidal mudflats and adjacent areas is needed.

Algal production on supratidal mudflats is likely to contribute to production by higher trophic levels in years where the inundation period is sufficiently long. A range of crustacean and fish species may access the supratidal mudflats during to feed during the period of inundation. Metapenaeid shrimp species were abundant in waters draining off these mudflats during the wet season (R. Kenyon pers. comm.). However, the links between PP and productivity in higher trophic levels is poorly understood and warrants further study in this system.

The processes that govern the benthic productivity on the Norman River supratidal mudflats are likely to be the same for other catchments in the southern 
Gulf of Carpentaria. The extent of the supratidal mudflats in the southern Gulf of Carpentaria is contained largely within the Flinders-Norman, Mornington Inlet, and Nicholson-Leichhardt catchments. This is an area of $3458 \mathrm{~km}^{2}$, based on the GEODATA $250 \mathrm{k}$ mapping of supratidal mudflat extents. Therefore PP across the southern Gulf could be as high as $748 \mathrm{t} \mathrm{C}$ in years where inundation is extensive and sustained, assuming uniformity in benthic algal biomass and responses to inundation.

Increasing development of coastal areas worldwide has dramatically reduced the area of coastal floodplains, including supratidal mudflats, as they have been traditionally considered as ecologically unimportant habitats. Additionally, water development, which reduces the scale of flooding, may also negatively impact the contribution of these habitats to coastal productivity (Fry 2002, Bayliss et al. 2014). Jardine et al. (2012) showed the critical importance of flooding of floodplains and connectivity to estuaries and coastal areas in supporting the growth and reproduction of a range of fish species, including commercially important species in the Gulf of Carpentaria.

In addition, future climate change impacts, such as changes in rainfall intensity, timing and duration, as well as sea level rise, are likely to have significant effects on supratidal mudflats. Projections for northern Australia include less frequent cyclones, which may reduce the scale of flooding (www.bom. gov.au/state-of-the-climate/). Conversely, greater and more sustained inundation will promote more production, while more variable climate regimes may reduce the frequency of rainfall, leading to less reliable productivity.

In summary, this study used a combination of experiments and modeling to provide estimates of PP and annual nutrient loads on supratidal mudflats in a wet-dry tropical river system. This study has highlighted that in years with sufficient inundation, these habitats may play an important role in coastal productivity.

Acknowledgements. We thank Melissa Duggan, Matthew Whittle, Robert Kenyon and Andy Revill for assistance with field work, Ken Tews for assistance with datalogger processing, Amanda Neilen for assistance with statistical analyses, Queensland Health Forensic and Scientific Services for nutrient analyses, and management and staff at Raptis and Sons for allowing us access to their facilities and regular advice and assistance. We thank 3 anonymous reviewers for their comments. This project was conducted as part of the Tropical Rivers and Coastal Knowledge (TRaCK) program. TRaCK received major funding for its research through the Australian Government's Commonwealth Environment Research Facilities initiative; the Australian Government's
Raising National Water Standards Program; Land and Water Australia; the Fisheries Research and Development Corporation and the Queensland Government's Smart State Innovation Fund.

\section{LITERATURE CITED}

Adame MF, Reef R, Grinham A, Holmes G, Lovelock CE (2012) Nutrient exchange of extensive cyanobacterial mats in an arid subtropical wetland. Mar Freshw Res 63:457-467

Albuquerque AGBM, Ferreira TO, Cabral RL, Nóbrega GN, Romero RE, Meireles AJA, Otero XL (2014) Hypersaline tidal flats (apicum ecosystems): the weak link in the tropical wetlands chain. Environ Rev 22:99-109

Bayliss P, Buckworth R, Dichmont C (eds) (2014) Assessing the water needs of fisheries and ecological values in the Gulf of Carpentaria. Final Report prepared for the Queensland Department of Natural Resources and Mines (DNRM), CSIRO, Brisbane

Briere PR (2000) Playa, playa lake, sabkha: proposed definitions for old terms. J Arid Environ 45:1-7

- Burford MA, Rothlisberg PC, Revill AT (2009) Sources of nutrients driving production in the Gulf of Carpentaria, Australia: a shallow tropical shelf system. Mar Freshw Res 60:1044-1053

> Burford MA, Webster IT, Revill AT, Kenyon RA, Whittle M, Curwen G (2012) Controls on phytoplankton productivity in a wet-dry tropical estuary. Estuar Coast Shelf Sci 113:141-151

Chapra SC (1997) Surface water-quality modeling. WCB/ McGraw-Hill, New York, NY

> Davranche A, Lefebvre G, Poulin B (2010) Wetland monitoring using classification trees and SPOT-5 seasonal time series. Remote Sens Environ 114:552-562

> Defries RS, Townshend JRG (1994) NDVI-derived land cover classifications at a global scale. Int J Remote Sens 15:3567-3586

Dortch Q (1990) The interaction between ammonium and nitrate uptake in phytoplankton. Mar Ecol Prog Ser 61: 183-201

> Duggan M, Connolly RM, Whittle M, Curwen G, Burford MA (2014) Effects of freshwater flow extremes on intertidal biota of a wet-dry tropical estuary. Mar Ecol Prog Ser 502:11-23

Frazier PS, Page KJ (2000) Water body detection and delineation with Landsat TM data. Photogramm Eng Remote Sens 66:1461-1467

Fry B (2002) Stable isotope indicators of habitat use by Mississippi Delta fish. J N Am Benthol Soc 21:676-685

Greenburg AE, Clesceri LS, Eaton AD (eds) (2005) Standard methods for the examination of water and wastewater, 21st edn. American Public Health Association, Washington, DC

- Halpern BS, Walbridge S, Selkoe KA, Kappel CV and others (2008) A global map of human impact on marine ecosystems. Science 319:948-952

Jardine TD, Pusey BJ, Hamilton SK, Pettit NE and others (2012) Fish mediate high food web connectivity in the lower reaches of a tropical floodplain river. Oecologia 168:829-838

Jeffrey SW, Welshmeyer NA (1997) Spectrophotometric and fluorometric equations in common use in oceanography. In: Jeffrey SW, Mantoura RFC, Wright SW (eds) Phytoplankton pigments in oceanography: monographs on 
oceanographic methodology, no 10. UNESCO Publication, Paris, p 597-615

Kennard MJ, Pusey BJ, Olden JD, Mackay SJ, Stein JL, Marsh N (2010) Classification of natural flow regimes in Australia to support environmental flow management. Freshw Biol 55:171-193

Kirkwood AE, Henley WJ (2006) Algal community dynamics and halotolerance in a terrestrial, hypersaline environment. J Phycol 42:537-547

Lovelock CE, Grinham A, Adame MF, Penrose HM (2010) Elemental composition and productivity of cyanobacterial mats in an arid zone estuary in north Western Australia. Wetlands Ecol Manage 18:37-47

McFeeters SK (1996) The use of the normalized difference water index (NDWI) in the delineation of open water features. Int J Remote Sens 17:1425-1432

Paling EI, McComb AJ (1994) Cyanobacterial mats: a possible nitrogen source for arid-coast mangroves. Int J Ecol Environ Sci 20:47-54

Paling EI, McComb AJ, Pate JS (1989) Nitrogen fixation

Editorial responsibility: Just Cebrian,

Dauphin Island, Alabama, USA (acetylene reduction) in nonheterocystous cyanobacterial mats from the Dampier Archipelago, Western Australia. Aust J Mar Freshw Res 40:147-153

Raven JA (1984) A cost benefit analysis of photon absorption by photosynthetic unicells. New Phytol 98:593-625

R Core Team (2015) R: a language and environment for statistical computing. R Foundation for Statistical Computing, Vienna. www.r-project.org

Redfield AC (1958) The biological control of chemical factors in the environment. Am Sci 46:205-222

Rhodes EG (1980) Modes of Holocene coastal progradation, Gulf of Carpentaria. PhD thesis, Australian National University, Canberra

Ridd P, Sandstrom MW, Wolanski E (1988) Outwelling from tropical tidal salt flats. Estuar Coast Shelf Sci 26:243-253

Ward DP, Hamilton SK, Jardine TD, Pettit NE, Tews EK, Olley JM, Bunn SE (2013) Assessing the seasonal dynamics of inundation, turbidity, and aquatic vegetation in the Australian wet-dry tropics using optical remote sensing. Ecohydrology 6:312-323

Submitted: April 16, 2015; Accepted: January 19, 2016 Proofs received from author(s): February 24, 2016 